\title{
Evaluation of blood flow on the remnant distal bowel during left-sided colectomy
}

\author{
Takayuki Ogino (10, Masaki Okuyama, Tomoki Hata, Junji Kawada, Miho Okano, Yongkook Kim and \\ Toshimasa Tsujinaka
}

\begin{abstract}
Adequate blood flow in anastomosis is of paramount importance to prevent anastomotic leakage. However, it is sometimes difficult to predict the viability of the intestine during surgery. During left-sided colectomy, blood flow on the remnant distal bowel is supplied only from the middle and inferior rectal arteries. The blood backflow after the root ligation of the inferior mesenteric artery is often said to be kept up to promontorium levels; however, this premise is actually based on experience, without reliable evidence. Here, we introduce the intraoperative evaluation of blood flow on the remnant distal bowel during left-sided colectomy using an indocyanine green fluorescence technique.
\end{abstract}

Keywords: Anastomotic leakage, Left-sided colectomy, Indocyanine green

\section{Introduction}

Anastomotic leakage (AL) is one of the most dreadful complications occurring after surgery for colorectal cancer. The reported incidence rate of AL after colorectal surgery ranges from 3 to $19 \%$. AL can cause increased morbidity, mortality, length of hospital stay, cost, and risk of cancer recurrence [1,2]. Adequate blood flow in anastomosis is of paramount importance for the prevention of AL; however, it is sometimes difficult to predict the viability of the ischemic bowel during surgery. The intraoperative evaluation of the intestinal blood flow is mostly performed by gross findings such as color, peristalsis, pulsation, and/or bleeding. It is largely dependent on the surgeon's skill and experience. Therefore, objective and accurate measurements of intestinal blood flow could reduce AL.

During left-sided colectomy with root ligation of the inferior mesenteric artery (IMA), the blood flow on the remnant distal bowel is supplied from the middle and inferior rectal arteries. The blood backflow is often said to be kept up to promontorium levels after the root ligation of the IMA; however, this premise is based on experience without any evidence. In clinics, excessive sacrifice of the remnant distal bowel due to lack of objective indicators of blood flow is a possibility.

\footnotetext{
* Correspondence: takayukiogino0113@yahoo.co.jp

Department of Surgery, Kaizuka City Hospital, Hori 3-10-20, Kaizuka-shi, Osaka 597-0015, Japan
}

Indocyanine green (ICG) has been used for several decades to evaluate cardiac output, liver function, liver blood flow, and ophthalmic blood flow [3]. In recent years, an ICG fluorescence technique with near-infrared light has become a promising technique for evaluating intestinal blood flow intraoperatively [4].

While several reports showed the evaluation of blood flow on the remnant proximal bowel during left-sided colectomy, only a few studies evaluated the remnant distal bowel $[3,4]$. We introduce an evaluation of blood flow on the remnant distal bowel during left-sided colectomy using an ICG fluorescence technique.

\section{Technique presentation}

A 73-year-old female came to our hospital due to constipation. She had no medical history other than diabetes mellitus. A colonoscopy revealed sigmoid colon cancer. An abdominal computed tomography (CT) scan showed T3 colon cancer near the SD junction (Fig. 1). A laparoscopic sigmoidectomy was performed.

The intraperitoneal observation confirmed no liver metastasis and no peritoneal dissemination. The small intestine was moved to the upper right side to keep the surgical field open. The mobilization of the left side of the colon up to the splenic flexure and the mobilization of the rectum were performed using a medial approach. Lymph node dissection around the root of the IMA was performed, exposing the IMA from the origin to the distal side (Fig. 2a). The

(c) The Author(s). 2018 Open Access This article is distributed under the terms of the Creative Commons Attribution 4.0 International License (http://creativecommons.org/licenses/by/4.0/), which permits unrestricted use, distribution, and 

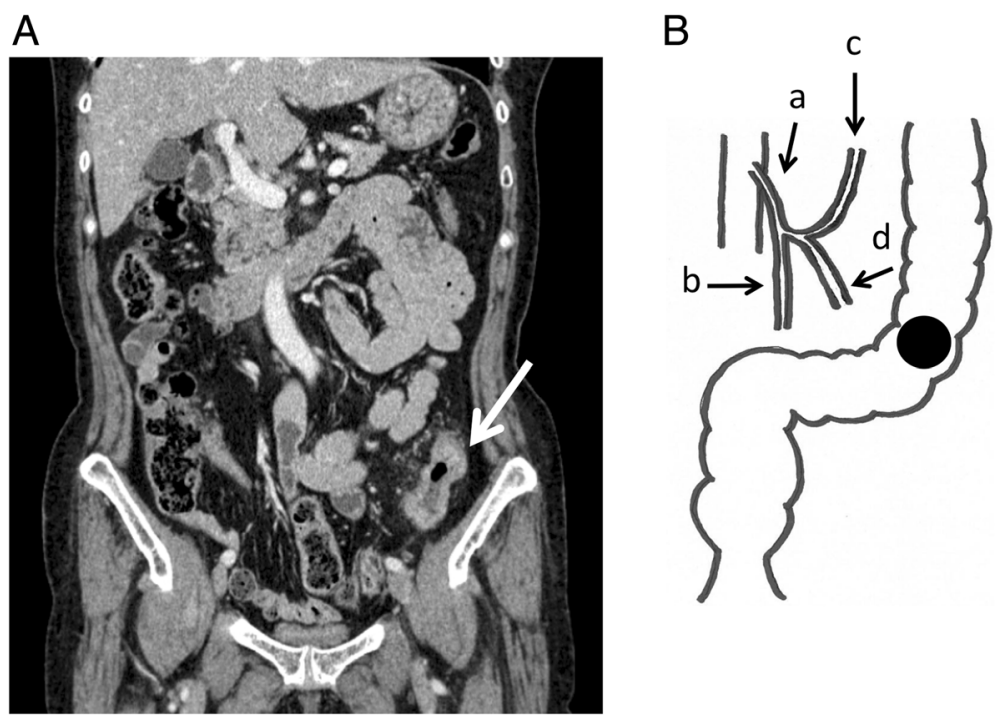

Fig. 1 A The abdominal CT scan showed T3 colon cancer near the SD junction. The arrow indicates the tumor location. B Anatomy of this patient. a: inferior mesenteric artery, b: superior rectal artery, c: left colic artery, d: sigmoid artery
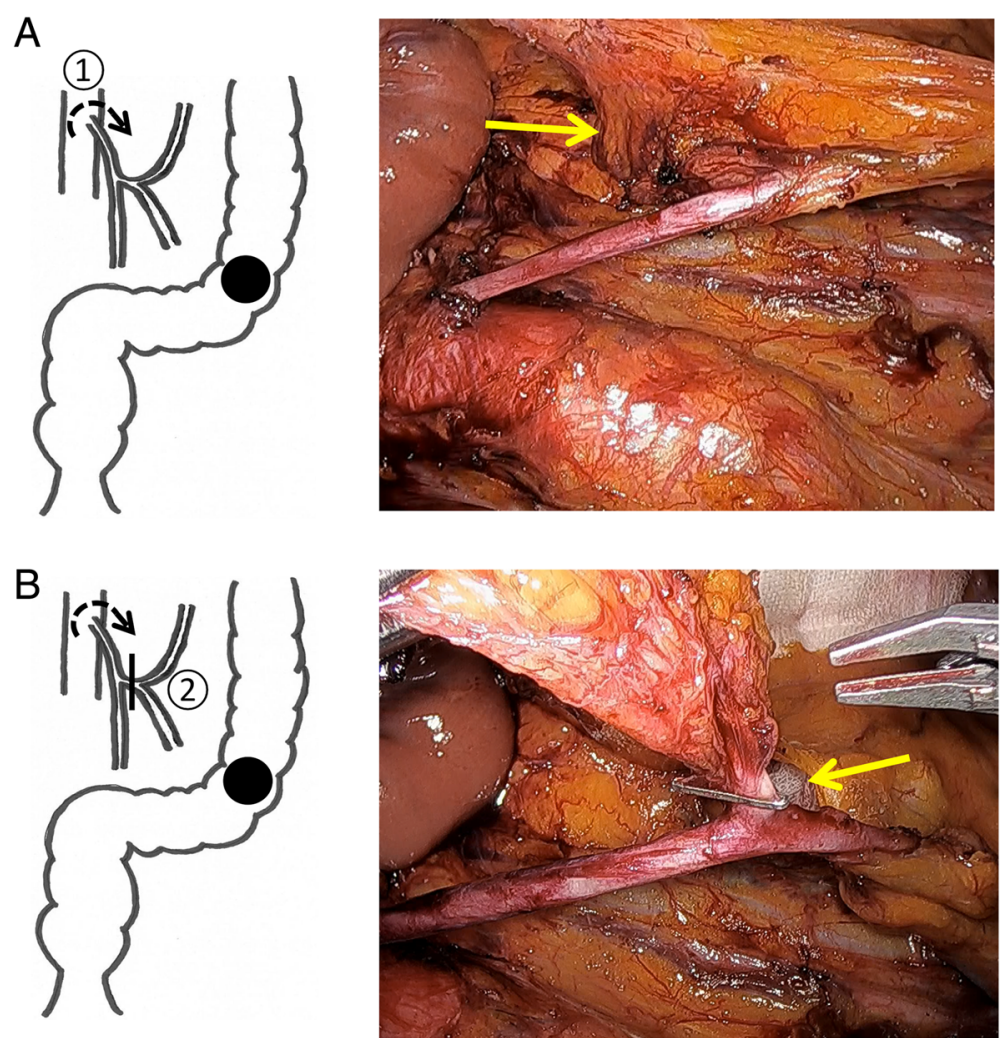

Fig. 2 a Lymph node dissection around the root of the IMA (1), arrow) after exposing the IMA from the root to the distal side. $\mathbf{b}$ The common trunk of the left colic artery and sigmoid artery were ligated, with preservation of the superior rectal artery (2), arrow) 
common trunk of the left colic artery (LCA) and sigmoid artery was ligated and lymph nodes were dissected around the root of the IMA, with preservation of the superior rectal artery (Fig. 2b). The proximal and distal bowel was resected, with a $10-\mathrm{cm}$ margin from the tumor (Fig. 3a). The distal side of the resected bowel was located $3 \mathrm{~cm}$ proximal to the promontorium. Subsequently, we performed an intraoperative blood flow evaluation; ICG $5 \mathrm{mg} / 2 \mathrm{ml}$ was administered intravenously, and the evaluation of the remnant bowel stump was performed before anastomosis using the NIR light camera system (Photodynamic Eye System, Hamamatsu Photonics, Japan). The blood flow on the remnant proximal bowel stump was fine. Next, we tried the blood flow evaluation following a clamp test of the IMA based on the presumption that the root ligation of the IMA was performed (Fig. 3b). The blood flow around the remnant distal bowel stump was quite poor during the IMA clamp (Fig. 3c). After the IMA clamp was released, the blood flow was fully recovered (Fig. 3d).

The patient was discharged without complications on postoperative day 10 . Our case showed a morbid risk for AL if the root ligation of the IMA had been performed without the intraoperative blood flow evaluation on the remnant distal bowel.

\section{Discussion}

The rate of lymph node metastasis around the root of the IMA is $3.6 \%$ in patients with $\mathrm{T} 3 / \mathrm{T} 4$ sigmoid colon cancer [5]. In Japan, the surgical procedure, with the dissection of lymph nodes along with IMA and the ligation and division on the root of the LCA, is commonly performed. This procedure is based on the concept of the significance of the lymph node dissection around the root of the IMA by means of the root ligation of the IMA, as well as the significance of preserving anastomotic perfusion by preserving the superior rectal artery. In our case, the operation was also performed according to this concept.

Regarding the blood flow in the left side of the colon or rectum, several studies have reported mainly on Sudeck's critical point. These reports anatomically clarified the continuity of blood flow in the remnant proximal bowel after left-sided colectomy with anatomical examinations using radiography or autopsy $[6,7]$. The examination of the blood flow in the remnant distal bowel after left-sided colectomy was also conducted in a few studies. These publications reported the variation in the middle rectal artery and anatomically examined the perfusion area of the superior, middle, and inferior rectal
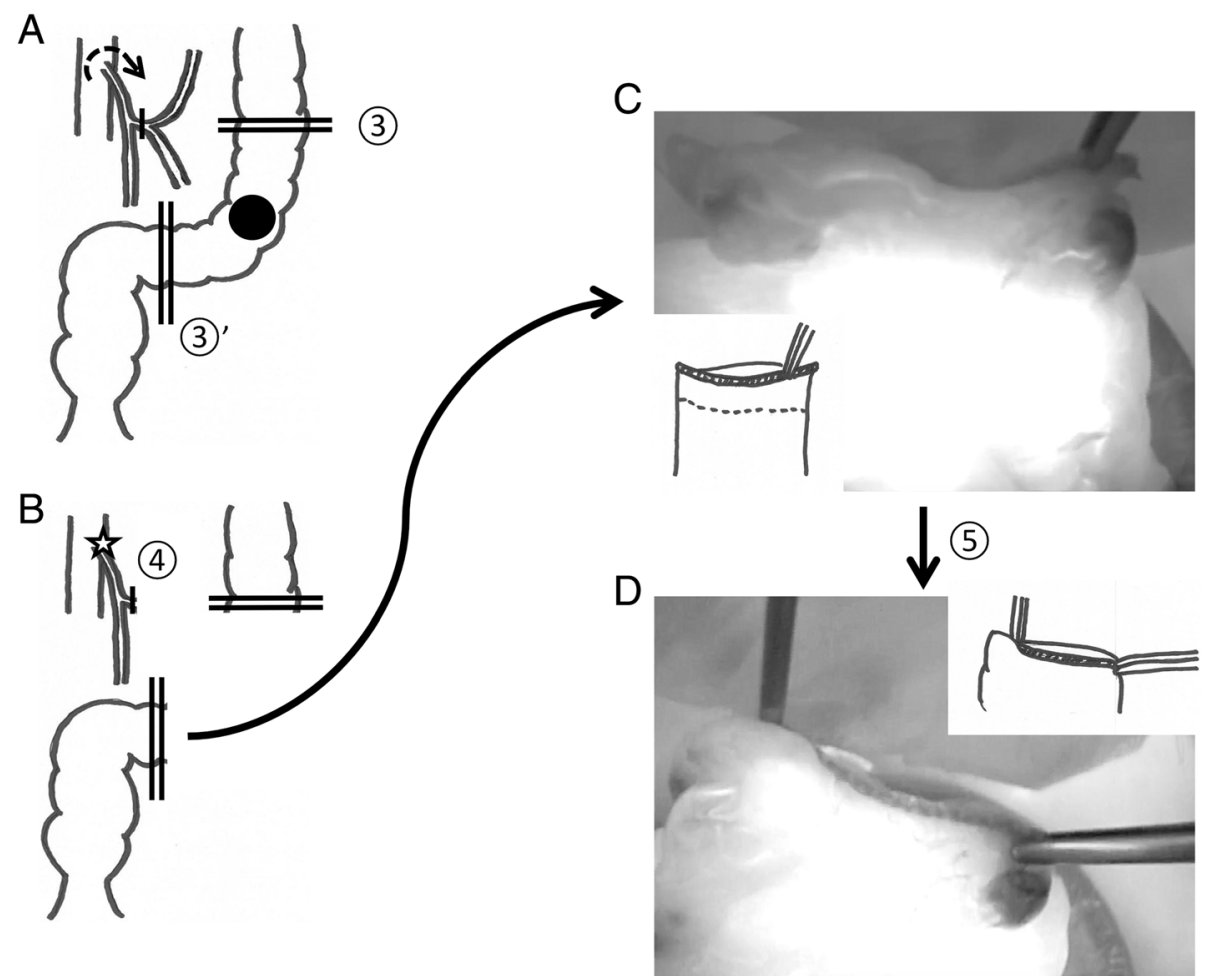

Fig. 3 a The resected line of the proximal (3) and distal (3)' bowel was determined, with a 10-cm margin from the tumor. b Blood flow evaluation after the clamp test of the IMA (4), star mark) based on the presumption that the root ligation of the IMA was performed. $\mathbf{c}$ Blood flow around the remnant distal bowel stump was quite poor after clamping the IMA. d After the IMA clamp was released (5), the blood flow around the remnant distal bowel stump fully recovered 
arteries [8, 9]. However, no functional evaluation has been performed so far.

Our case revealed the possibility of preserving more of the remnant distal bowel using the ICG fluorescence technique. This technique also can be applied in cases where there is damage to marginal vessels during surgery or in cases with severe arterial sclerosis.

During left-sided colectomy, the distal side of the bowel was often excessively resected forcing the anastomosis to be performed at points lower than the promontorium. However, the lower anastomosis makes the procedure difficult to perform and may cause anastomotic failure. Preserving a longer remnant distal bowel is desirable to minimize anastomotic tension and promote postoperative bowel function if enough blood supply and the margin from the tumor can be confirmed. Larger studies of the ICG fluorescence technique are needed to confirm and verify the effects on AL.

\section{Authors' contributions}

TO designed the work and wrote the manuscript. MO, TH, JK, MO, YK, and TT assisted with the acquisition of the images and also with manuscript revision. All authors read and approved the final manuscript.

\section{Ethics approval and consent to participate}

The protocol for this research project was approved by the Ethics Committee of the institution where the work was undertaken. The procedures conformed to the provisions of the Declaration of Helsinki of 1995 (as revised in Brazil,2013)

\section{Consent for publication}

Written informed consent was obtained from the patient for publication of this report and any accompanying images. A copy of the written consent is available for review by the Editor-in-Chief of this journal.

\section{Competing interests}

The authors declare that they have no competing interests.

\section{Publisher's Note}

Springer Nature remains neutral with regard to jurisdictional claims in published maps and institutional affiliations.

Received: 27 February 2018 Accepted: 5 September 2018

Published online: 13 September 2018

\section{References}

1. Kang CY, Halabi WJ, Chaudhry OO, et al. Risk factors for anastomotic leakage after anterior resection for rectal cancer. JAMA Surg. 2013; 148:65-71.

2. Mirnezami A, Mirnezami R, Chandrakumaran K, et al. Increased local recurrence and reduced survival from colorectal cancer following anastomotic leak: systematic review and meta-analysis. Ann Surg. 2011; 253:890-9.

3. Keller DS, Ishizawa T, Cohen R, et al. Indocyanine green fluorescence imaging in colorectal surgery: overview, applications, and future directions. Lancet Gastroenterol Hepatol. 2017;2:757-66.

4. Jafari MD, Wexner SD, Martz JE, et al. Perfusion assessment in laparoscopic left-sided/anterior resection (PILLAR II): a multi-institutional study. J Am Coll Surg. 2015;220:82-92.

5. Japanese Society for Cancer of the Colon and Rectum. Japanese classification of colorectal carcinoma. 8th ed. Tokyo: Kanehara \& Co. Ltd; 2013.

6. Griffiths JD. Surgical anatomy of the blood supply of the distal colon. Ann R Coll Surg Engl. 1956;14:241-56.
7. Goligher JC. The blood supply of the sigmoid colon and rectum with reference to the technique of rectal resection with restoration of continuity. Br J Surg. 1949;37:157-62.

8. Michels NA, Siddharth $\mathrm{P}$, Kornblith $\mathrm{PL}$, et al. The variant blood supply to the descending colon, rectosigmoid and rectum based on 400 dissections. Dis Colon Rectum. 1965;8:251-78.

9. Boxall TA, Smart JG, Grifhths JD. The blood supply of the distal segment of the rectum in anterior resection. Br J Surg. 1963;50:399-404.
Ready to submit your research? Choose BMC and benefit from:

- fast, convenient online submission

- thorough peer review by experienced researchers in your field

- rapid publication on acceptance

- support for research data, including large and complex data types

- gold Open Access which fosters wider collaboration and increased citations

- maximum visibility for your research: over $100 \mathrm{M}$ website views per year

At $\mathrm{BMC}$, research is always in progress.

Learn more biomedcentral.com/submissions 